\title{
Woman performing her devotion to the Hindu god Shiva, in the form of a Linga
}

Holly Shaffer

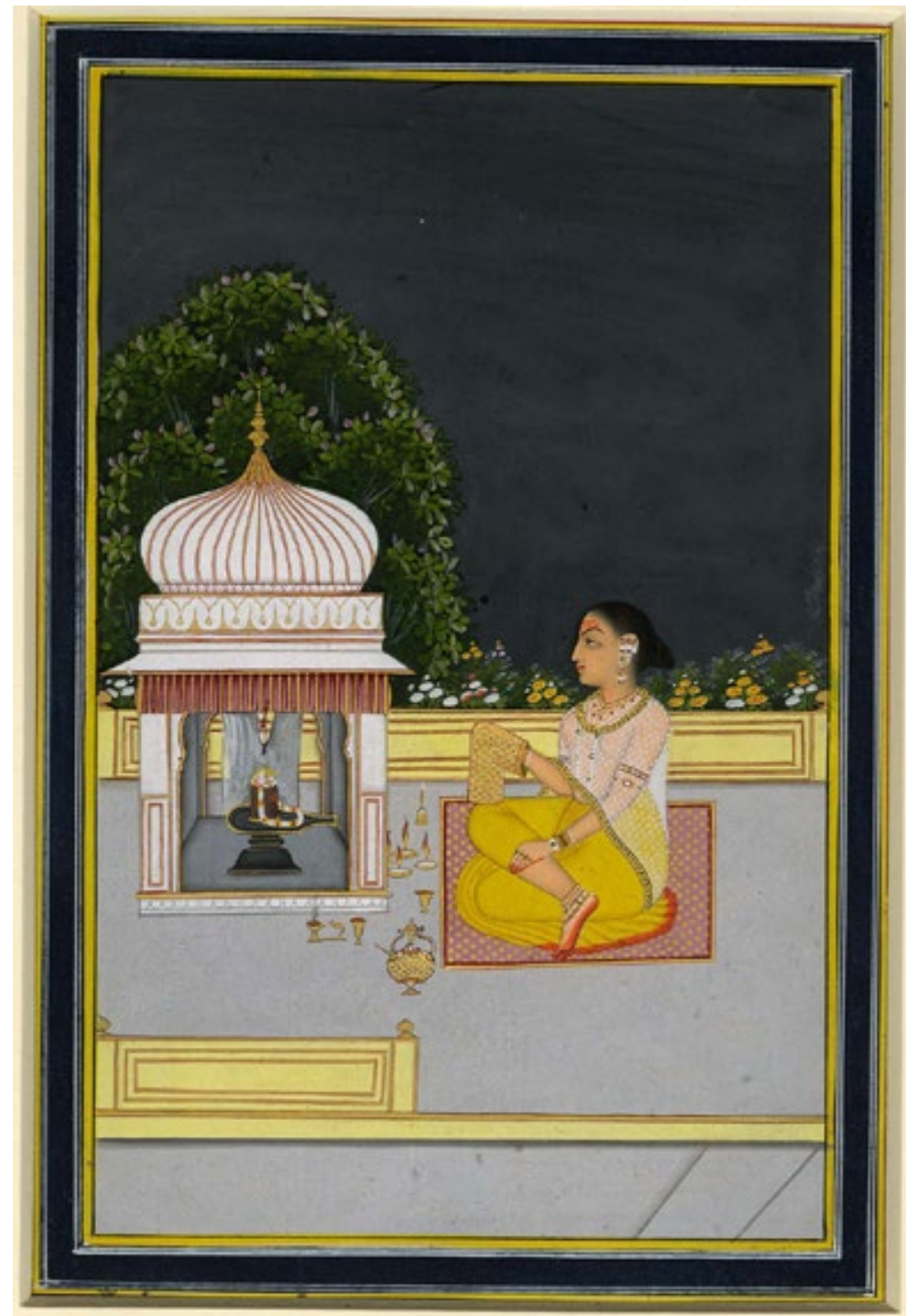

Fig. 1 Woman performing her devotion to the Hindu god Shiva, in the form of a Linga, 18th century, Photograph (C) Trustees of the British Museum

In this single folio, a woman is engaged in prayer. She sits on a pink cloth, her head in profile, with her body turned three-quarters to the viewer. Her right hand is covered by a golden textile, under which she counts beads on a rosary in meditation. She has garlanded the linga, or symbol of the Hindu god Shiva, and its three stripes of orange are mirrored on her forehead. Small lamps burn, a bell is poised to ring, a small vessel holds water or milk. All call the god to attention by smell, sight, touch, and sound. The setting is calm; she is on a terrace in the dark blue of early morning, the shrine is nearly 
her own size, with a white bulbous dome haloed by a green flowering tree that is rooted in a garden outside the low wall, the woman's bejeweled head almost a flower among them.

It is not known by whom this painting was made, but it was likely produced in Jaipur in the late eighteenth century. ${ }^{1}$ It is possible that it was intended as one of a set of musical modes, called a ragamala, that pictorialize music in paint and evoke its associated mood or rasa, time of day and season. ${ }^{2}$ Its iconography conforms to one mode, ragini bhairavi, where a woman, or perhaps Shiva's wife Parvati, performs prayer or puja to Shiva in the form of a linga just before dawn. ${ }^{3}$ It is also possible, however that she was produced as a single folio. ${ }^{4}$ In this period, the popularity of certain iconographies such as the woman at prayer set them loose from classificatory sets to become independent pages for purchase, particularly when the subject matter overlapped with other popular themes, such as the portrait of a beauty. ${ }^{5}$ The figure's sheer upper garment that just reveals the form of her breasts further eroticizes the image. ${ }^{6}$

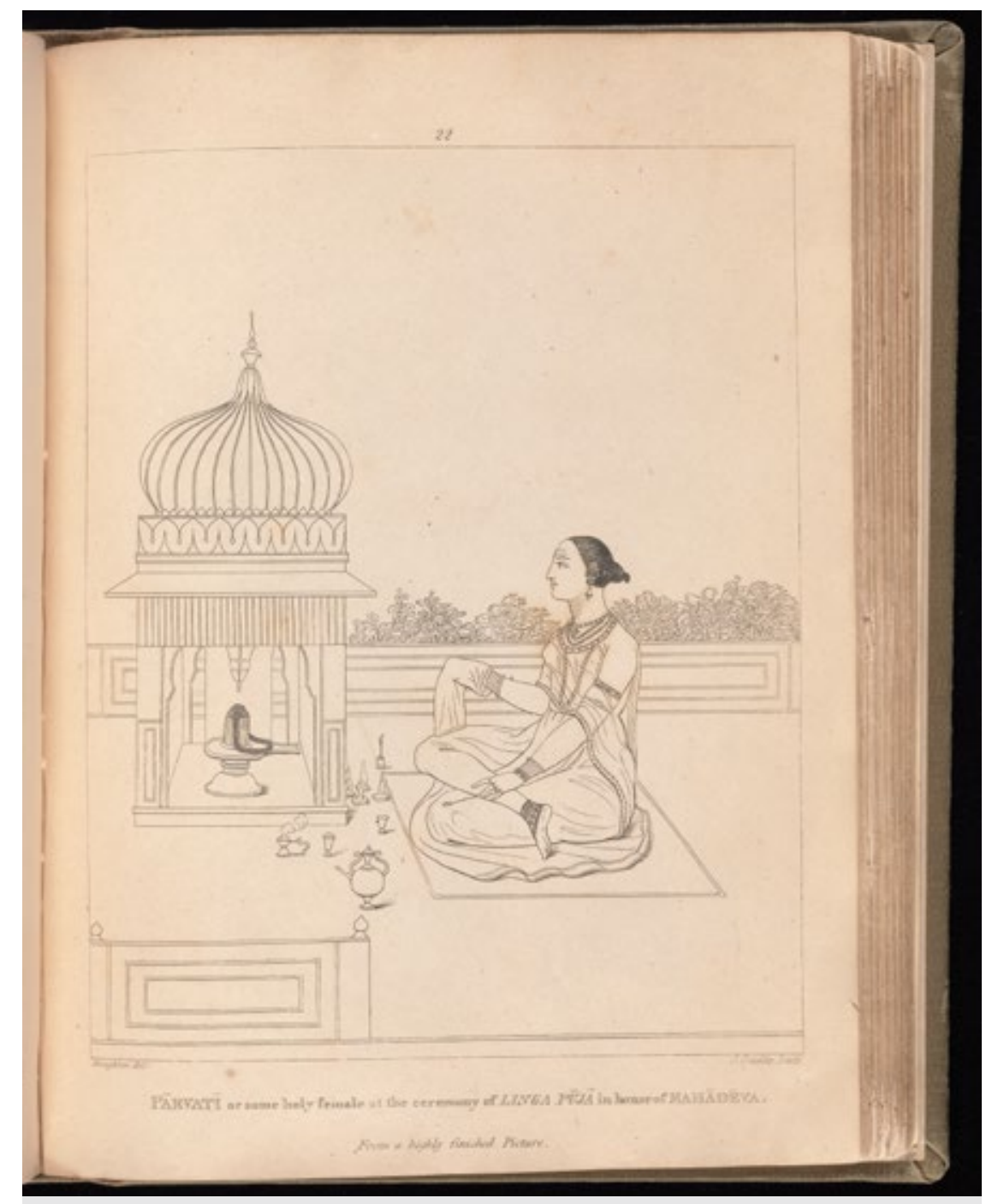

Fig. 2 Parvati or some holy female at the ceremony of Linga Puja in honor of Mahadeva 
Sometime after this painting was made, an East India Company official named Edward Moor purchased it while in the western Deccan engaged in the Anglo-Maratha alliances against Tipu Sultan of Mysore. Moor most likely acquired the image through agents such as Indian "correspondents" or British "travelling friends." It is one of over six hundred paintings and sculptures in Moor's collection, now at the British Museum. The collection focuses attention on the subjects of deities, mythology, and devotion. In 1810, Moor published the painting in the form of an outline engraving, as Plate 22 of 105, in his Hindu Pantheon. In this book Moor "endeavor[ed] to explain" Indian "Mythology" through ethnography, contemporary scholarship, and, uniquely, the "utility of pictures and visible objects."

For Moor, this "delicately executed" painting of "a pious female" represents her desire for "the blessing of fruitfulness," a child, which relates to many of the potential meanings outlined above. However, besides its beauty and emotional resonance, it also offered him an opportunity to describe the "implements" such as the "five lighted lamps (pancharty)" used in the ceremony, taught to him by a Brahmin and noted by him in the red border. ${ }^{9}$ Thus, the painting becomes a diagram of worship as well as an aesthetic, poetic, and erotic object. It fits in closely with images used to aid Moor's, and his wide audience's, "comprehension of certain terms and illusions"10 related to Hindu devotion. Such images facilitated the intertwined enlightenment and colonial desire of East India Company officials to document and understand the world, particularly those people they wished to rule. ${ }^{11}$

(C) Holly Shaffer

\section{Citation Guide}

1. Holly Shaffer, "Woman performing her devotion to the Hindu god Shiva, in the form of a Linga," Object Narrative, in Conversations: An Online Journal of the Center for the Study of Material and Visual Cultures of Religion (2014), doi:10.22332/con.obj.2014.5

Shaffer, Holly. "Woman performing her devotion to the Hindu god Shiva, in the form of a Linga." Object Narrative. In Conversations: An Online Journal of the Center for the Study of Material and Visual Cultures of Religion (2014). doi:10.22332/con.obj.2014.5

\section{Notes}

1. For a description of ragamala paintings from Jaipur see Klaus Ebeling, Ragamala Painting, (Basel: Ravi Kumar, 1973), 94-100, 109.

2. For a general overview of the ragamala see Anna L. Dallapiccola, "Ragamala painting, a brief introduction," in Ragamala: Paintings from India, ed. Catherine Glynn, Robert Skelton, and Anna L. Dallapiccola (London: Philip Wilson, 2011), 13-21. 
3. See Ebeling, Ragamala Painting, 34-35; and Catherine Glynn, Robert Skelton, and Anna L. Dallapiccola, ed., Ragamala (London: Philip Wilson, 2011), 76-78.

4. The lack of the textual poem, which garners the mood of the raga and is often written on the top of the painting or on the verso, buttresses the idea that this was designed as an individual folio. See Dallapiccola, "Ragamala painting" and Robert Skelton, "Ragamalas in the Deccan and what happens when ragas migrate without their texts," in Ragamala: Paintings from India, ed. Catherine Glynn, Robert Skelton, and Anna L. Dallapiccola (London: Philip Wilson, 2011), 23-28.

5. See John Seyller, Mughal and Deccani Paintings (Zurich: Museum Reitburg, 2010), $82-85$.

6. The play between the erotic and the ascetic is common in depictions of women engaged in the feeling of "love in separation," as well as in the dual nature of Shiva, as ascetic and lover. See Seyller Mughal and Deccani, 90-92; Wendy Doniger, Siva: The Erotic Ascetic (New York: Oxford University Press, 1981); and Dallapiccola "Ragamala painting," 19.

7. Edward Moor, The Hindu Pantheon (London: J. Johnson, 1810), 431.

8. Moor, The Hindu Pantheon, ix. Edward Moor's publication fits within the colonial project of "knowledge" acquisition about India, which is explicit in Warren Hastings' letter of 1784 regarding Charles Wilkins's translation of the Bhagavad Gita: "Every accumulation of knowledge, and especially such as is obtained by social communication with people over whom we exercise a dominion founded on the right of conquest, is useful to the state;" (P. J. Marshall, The British discovery of Hinduism, 1970) and implicit in the forum for research "The Asiatic Society of Bengal" founded in 1784 by Sir William Jones, and its journal Asiatic Researches, which Moor regularly draws on for source material.

9. See the painting in the British Museum, number: 1940,0713,0.52; and Moor, The Hindu Pantheon, 69.

10. Moor, The Hindu Pantheon, ix.

11. Postcolonial scholarship has foreground the intertwined and imperial nature of Company officials' scholarly and artistic endeavors alongside their political, economic and military purpose. For a literature review see Phillip B. Wagoner, "Precolonial Intellectuals and the Production of Colonial Knowledge," Society for Comparative Study of Society and History 45, no. 4 (October 2003), 783-814. doi:10.1017/ s0010417503000355

\section{Yale}

Copyright 2016 Yale University All rights reserved. 